\title{
ONDE A DINÂMICA ENCONTRA O CONTROLE
}

\author{
ELBERT E. N. MACAU ${ }^{1}$; GERALDO NUNES DA SILVA ${ }^{2}$ \\ ${ }^{1}$ Instituto Nacional de Pesquisas Espaciais (INPE), São José dos Campos, SP, Brasil. E-mail: elbert.macau@inpe.br \\ ${ }^{2}$ Universidade Estadual Paulista Júlio de Mesquita Filho (UNESP), São José do Rio preto, SP, Brasil. E-mail: \\ gsilva@ibilce.unesp.br
}

O conceito de Sistemas Dinâmicos tem sua origem na Dinâmica de Newton. Em seu Philosophioe Naturalis Pricipia Mathematica [1], de 1687, Newton enunciou as três leis da física que formam a base da mecânica clássica. Estas leis nos permitem descrever o movimento de um corpo em respostas às forças que agem sobre ele, sendo que este corpo é representado como sendo um ponto no espaço que possui massa. $\mathrm{O}$ foco da concepção newtoniana está na relação entre força e variação da velocidade - aceleração - o que permite chegar-se a uma equação diferencial geral associada a situação que se analisa. Isto deixa em segundo plano, como um subproduto, a descrição geométrica da trajetória do corpo, que é o resultado que se deseja na maioria das vezes, como sendo uma solução particular da equação diferencial devido às condições iniciais que estão presentes na situação particular. Este enfoque, associado ao cálculo diferencial e integral e à Teoria da Gravitação Universal, compôs pelo primeira vez na história da humanidade um arcabouço teórico que permitia explicar uma gama imensa de fenômenos físicos, além de moldar a base da própria Física.

A Teoria dos Sistema Dinâmicos, iniciada por Poincaré [2], pode ser vista como um refinamento ou uma evolução dos conceitos de abstração previamente introduzidos por Newton. Um corpo passa ter seu movimento descrito no espaço de estado, cujas coordenadas representam seu estado em um dado instante, que se altera ao longo do tempo para estados subsequentes devido à ação de uma regra dinâmica. Nesta abstração, um estado representa o conhecimento mínimo que se precisa saber do corpo para que seja possível determinar sua evolução subsequente diante da ação da regra dinâmica. Tem-se aqui um formalismo preciso, que nos permite caracterizar de forma precisa a evolução dinâmica de sistema naturais, além de propiciar uma estrutura que permite modelar de forma adequada a dinâmica presente em sistemas tecnológicos.

Já a Teoria de Controle remonta os tempos da Revolução Industrial, como resposta à necessidade de se controlar as caldeiras e máquinas a vapor. Por volta de 1624, anterior, por conseguinte, ao trabalho de Newton, o holandês Cornelius Drebbel desenvolveu um controlador automático de temperatura para um forno [3], motivado por sua crença de que um metal poderia ser transformado em ouro se fosse mantido por longo período de tempo em uma temperatura constante. Seu mecanismo de controle mostrou-se bem sucedido, graças a uso do conceito de retroalimentação.

O conceito de retroalimentação foi subsequentemente explorado por vários outros pesquisadores, durante o aperfeiçoamento da máquina a vapor, no século XVIII e XIX, em especial relacionados aos problemas de se regular com propriedade o fluxo de líquido a temperatura e a pressão da caldeira. Aqui, especial destaque deve ser dado ao trabalho de James Watt, que dentre tantas contribuições identifica-se uma particular, onde o mecanismo da realimentação se fez implementar via o uso do vapor para fazer girar pesos que, quanto maior a velocidade, mais se deslocavam para cima, alterando com este movimento a abertura da válvula de controle do fluxo de vapor [4].

Todas essas iniciativas eram empíricas: sabia-se que o mecanismo chave para o controle é a realimentação, mas não existia uma teoria para explicar seu funcionamento e como avaliar sua ação. Este cenário começou a mudar graças ao trabalho do astrônomo George Bidell Airy, que em 1840 desenvolveu um sistema de controle por realimentação para que seu telescópio se alterasse de forma automática, compensando a rotação da terra [5]. Porém, o mecanismo que ele concebeu apresentou grandes oscilações, ou seja, se mostrou instável. Ele foi o primeiro a discutir a questão da instabilidade em sistemas de controle e a usar as equações diferenciais em suas análises. Seus estudos abriram caminho para o desenvolvimento de mecanismos formais de determinação da estabilidade de sistemas de controle realimentados e que subsequentemente envolveram James Clerk Maxwell [6], Edward John Routh [7], Adolf Hurwitz [8] e Aleksandr Lyapunov [9].

A Teoria de Controle se desenvolveu celeremente ao longo do século XX, em especial, motivada pelas necessidades advindas da II Guerra Mundial e da Conquista Espacial. As da primeira foram adequadamente enfocadas pelas técnicas de análise no domínio da frequência, enquanto os requisitos extremos próprios dos sistemas espaciais, onde a não linearidade impera, levou ao desenvolvimento da chama Teoria do Controle Moderno, que tem por fundamento os mesmos conceitos de espaço de estado e regra dinâmica que já eram então usados pela Teoria dos Sistemas Dinâmicos.

Tem-se aqui, por conseguinte, o encontro de duas área, que se baseiam em fundamentos comuns e que hoje envolvem um extensivo grau de interpenetração e interdependência. Este cenário vem influenciando de forma recíproca os desenvolvimentos atuais de ambas as áreas.

Com este contexto em vista e objetivando fomentar o desenvolvimento conjunto e a sinergia entre de ambas as áreas, além de permitir que pesquisadores e seus alunos desfrutem de um ambiente único e profícuo para discutir e debater suas ideias, é que em 2001 surgiu o DINCON Conferência Brasileira de Dinâmica e Controle. Este evento interdisciplinar é único, pois visa permitir a discussão de abordagens não clássicas e inovadores relacionadas às mais diversas áreas do conhecimento e que visem modelar e controlar sistemas dinâmicos não lineares. 
E este caráter inovador está aqui também presente neste volume, no sentido de que os trabalhos apresentados no XI DINON, que ocorreu em Fortaleza, entre 13 a 17 de outubro de 2013, em conjunto com o XI SBAI, foi o evento escolhido pela SBMAC para inaugurar o seu Proceeding-Series of the Brazilian Society of Applied and Computational Mathematics.

Nesta oportunidade, queremos agradecer ao esforço de todos os que direta ou indiretamente contribuíram para o sucesso do XI DINCON, incluindo autores, revisores, comitê de organização, comitê científico, equipe de suporte, convidados, entre outros. Sem o apoio de todos, não seria possível chegar a $11^{\circ}$ edição de um evento que já entrou para a história e tem um futuro brilhante de continuidade pela frente.

Em nome do Comitê Temático de Dinâmica, Controle e Aplicações da Sociedade Brasileira de Matemática Aplicada e Computacional, queremos agradecer a todos e desejar que o material aqui contido possa servir de base para pesquisas inovadoras e revolucionárias a serem apresentadas na próxima edição de nosso evento, em 2015. E também agradecemos aos editores dos "Proceedings", por nos ter propiciado de forma tão harmônica a honra e o privilégio de "inaugurarmos" mais esta série da SBMAC, que com certeza se destina a ser referência no cenário científico nacional e sul americano.

Obrigado a todos!

\section{Referências}

[1] I. Newton, "Mathematica Principles of Natural Philosophy," 1725.

[2] H. Poincaré, "Mémore fur les coubes définies par une équation différentielle," Journ. De mathématiques pures et appliquées, 3rd ser. 7, 375-422, 1881.

[3] G. Tierie, "Cornelis Drebbel", Paris, 1932.

[4] H. W. Dickinson, "James Watt: Craftsman and Engineer," Cambridge, 1935.

[5] G. E. Satterthwaite, "Airy's zenith telescope and "the Birth-Star of Modern Astronomy"," Journ of Astronomical History and Heritage, 6(1):13.

[6] J. C. Maxwell, "The scientific papers of James Clerk Maxwell,'Dover Publication.

[7] J. E. Routh, "Treatise on the Stability of a Given State of Motion," MacMillan, 1877.

[8] E. I. Jury, "Remembering four stability theory pioneers of the nineteenth century," IEEE Trans. Automat. Control, 43 (10), 821-823, 1996.

[9] P. C. Parks, “A. M. Lyapunov's stability theory - 100 years,” IMA J. Math Control Inform. 9 (4) 275-303, 1992. 